\title{
CONHECER PARA AFIRMAR DIREITOS: UMA PROPOSTA METODOLÓGICA PARA ESTUDOS SOCIOECONÔMICOS DE TERRITÓRIOS QUE LUTAM PELA TERRA*
}

\author{
Elizabeth Carla Vasconcelos Barbosa \\ Hayda Alves \\ Jéssica Oliveira Monteiro \\ Katia I. Marro \\ Ramiro Dulcich
}

\section{Introdução}

O capítulo busca refletir e socializar um instrumento metodológico para o conhecimento das condições sociais e econômicas de indivíduos e populações de territórios que lutam pela terra, a fim de traçar o perfil das comunidades e das suas necessidades tanto para reivindicar acesso às políticas públicas e garantias de direitos, quanto para pensar outras ações auto-organizativas importantes na construção de acampamentos e assentamentos.

A proposta emerge da experiência de um Programa de Extensão desenvolvido por professores e estudantes dos cursos de graduação em Serviço Social e Enfermagem, da Universidade Federal Fluminense/Campus de Rio das Ostras. Esta experiência vem se desenvolvendo na região desde 2010 em diálogo com movimentos sociais que lutam pela terra, contribuindo com o fortalecimento destes territórios de reforma agrária na perspectiva dos direitos humanos e de cidadania, assim como também, articulando estes processos extensionistas à formação profissional de discentes dos cursos envolvidos. Dentre as frentes de atuação construídas junto às comunidades organizadas nos territórios, destacamos: atividades de formação humana, política e cultural; de educação popular em saúde; estudos socioeconômicos e epidemiológicos; articulação com a rede de serviços socioassistenciais locais e regionais; registros da memória histórica das comunidades rurais; trabalhos de reflexão e produção com mulheres, com jovens, dentre outras.

Ao propormos realizar um trabalho de acompanhamento e assessoria do processo de construção de assentamentos e acampamentos de Reforma Agrária, os momentos iniciais de levantamento e identificação das demandas sociais, econômicas e de saúde da comunidade são fundamentais. Trata-se de reconhecer necessidades coletivas que merecem especial atenção para a melhoria das condições de vida e o acesso aos direitos, mas também, pela potência em construir a partir deste encontro um processo que preserve e potencialize o protagonismo dos sujeitos envolvidos, na contramão de processos de apaziguamento que descaracterizam e fragmentam as lutas sociais.

*DOI - 10.29388/978-65-86678-92-5-0-F.47-64 
Vem! Entre na experiência de estudar as condições socioeconômicas de territórios que lutam pela terra. Deixe-se tomar pelos seus dilemas, se encante com as suas riquezas, se inspire nas suas resistências!

\section{De que território estamos falando?}

Nossa aproximação com a comunidade do Assentamento Osvaldo de Oliveira se dá a partir de 2010, quando um grupo de 200 famílias organizadas pelo Movimento das/os Trabalhadoras/es Rurais Sem Terra (MST) ocupou a então fazenda "Bom Jardim", em Córrego do Ouro, no município de Macaé-RJ. As famílias, marcadas pelo desemprego e o processo de pauperização resultante, provinham dos municípios vizinhos de Rio das Ostras, Macaé, Cabo Frio e Casimiro de Abreu, todos localizados na Região dos Lagos do estado do Rio de Janeiro. Nascia assim, no dia 7 de setembro, o Acampamento Osvaldo de Oliveira que se tornaria assentamento em 2014, sob a modalidade de Projeto de Desenvolvimento Sustentável (PDS).

Ocupações de latifúndios improdutivos organizados por movimentos sociais do campo não são novidades no Brasil e na América Latina, onde a concentração da propriedade da terra e a democratização do seu acesso é tão desigual entre as classes sociais. De modo geral, através das ocupações os movimentos sociais pressionam o Estado para que garanta o preceito constitucional sobre a função social da terra e realize as desapropriações previstas por Lei para fins de Reforma Agrária. Neste caso, trata-se de uma área de 1500 hectares, com a presença de uma mata atlântica nativa de incalculável valor (em termos de biodiversidade) na grande maioria do terreno. Em 2006, foi considerada pelas avaliações do INCRA como área improdutiva e declarada de interesse social em 2010, tornando-se possível seu uso para fins da Reforma Agrária.

O contato com a Universidade Pública nasceu pela iniciativa do movimento social que buscou apoio e assessoria para enfrentar a alta vulnerabilidade em que se encontravam as famílias. Muitos idosos, crianças, jovens e adultos estavam abrigados em barracos de bambu e lona, sem assistência nem acesso a direitos; sem proteção social alguma. Num primeiro momento, uma vez ouvidas as famílias e as/os representantes do MST, respondemos às demandas mais urgentes e construímos de forma conjunta ações e atividades na área da saúde e de formação política e humana, que nos permitiram conhecer importantes aspectos socioculturais, econômicos e sanitários da comunidade. Como equipe extensionista, acompanhamos esse período extremamente duro da vida desse Acampamento; tempo marcado por mais de um despejo violento por parte do Estado, sem apoio dos poderes públicos, tendo que realizar diversos deslocamentos e uma precariedade generalizada nas condições de vida, alimentação, moradia, cultura, lazer, sexualidade ${ }^{1}$.

\footnotetext{
${ }^{1}$ Após o despejo da então fazenda "Bom Jardim", formaram vários acampamentos emergenciais para se manter agrupados; tiveram que migrar do Parque de Exposições de Córrego do Ouro, depois para o terreno de uma Igreja em Macaé; posteriormente para as margens da BR 101 e, finalmente, para a comunidade Califórnia, nas margens da linha de trem Leopoldina-Campos, no município de Rio das Ostras.
} 
Em 2011, com 120 famílias acampadas na comunidade Califórnia, realizamos um primeiro diagnóstico social e de saúde através de oficinas que utilizavam a fotografia como ferramenta pedagógica para dar visibilidade às questões sanitárias do acampamento. Logrou-se reconhecer naquele momento o processo de saúdedoença da comunidade a partir dos determinantes sociais de saúde, que apontavam: problemas de atrasos no calendário de vacinação de crianças; um alto índice de hipertensão entre os adultos homens e mulheres; vários casos de diabetes; doenças de pele em crianças, adolescentes e adultos; queixas de dificuldade visual em crianças e adolescentes; condições de moradia extremamente precárias; descarte e manejo inadequado do lixo a céu aberto; falta de água potável, dentre outras situações deficitárias.

Desde o Programa de Extensão iniciamos intervenções em Saúde por meio de práticas socioeducativas, visando contribuir à prevenção de doenças, a promoção da saúde das famílias e estimulando a auto-organização da comunidade, com perspectivas de transformação dessa realidade. Para além dessas ações, realizamos um levantamento de demandas coletivas como, por exemplo, transporte para as crianças irem à escola, e um diagnóstico participativo em relação a questões de Saúde, onde foram identificados diversos problemas como: manuseio e destino do lixo; higiene pessoal e da comunidade; cuidados e higiene bucal; acesso e utilização da Rede de Saúde local - prevenção; gênero e sexualidade; uso de álcool e outras drogas; violência doméstica. O perfil levantado foi encaminhado ao poder público local, para subsidiar a reivindicação do direito ao acesso à rede de saúde e assistência.

Em 2014 a comunidade conquistou a posse da terra e nasce o Assentamento Osvaldo de Oliveira, como um modelo diferenciado de assentamento de desenvolvimento sustentável (PDS), sendo o primeiro do estado do Rio de Janeiro. Este formato de assentamento visa integrar a agricultura familiar com a conservação ambiental, tendo sua gestão compartilhada entre vários organismos que formam um Comitê Gestor do PDS (INCRA, entidades ambientais governamentais, instituições de pesquisa e movimentos sociais), responsável por acompanhar e fiscalizar seu funcionamento. Assim, nascia o PDS com o objetivo de materializar princípios agroecológicos, preservar e recuperar o bioma, diminuir os índices de desemprego, contribuir com a segurança alimentar e distribuir alimentos saudáveis e acessíveis ao conjunto de trabalhadores.

Poucos meses depois de constituído o assentamento, construímos junto à comunidade um outro estudo socioeconômico que lançaria informações importantes para planejar este novo território, elaborar intervenções em saúde e em articulação à rede de políticas públicas e subsidiar o planejamento de outras atividades extensionistas. A análise dos dados coletados evidenciou a situação de vulnerabilidade da comunidade em questões de saúde, acesso à política de assistência social, de previdência, de educação, entre outras. Estas informações subsidiaram os processos de auto-organização e a construção de reivindicações junto ao poder público do município, que se traduziram em demandas para as Secretarias de Saúde, Assistência Social, Previdência, Educação, Meio Ambiente, Agroeconomia; Urbanismo, entre outras. Mas a experiência também mostrou que o instrumento 
metodológico que tínhamos construído deixava fora dados e informações de extrema relevância para a organização de um assentamento de Reforma Agrária. Dos rascunhos que docentes e estudantes foram rabiscando em cada formulário individual, da troca com as famílias, nasceu esta nova proposta metodológica que aqui apresentamos. Esperamos que ele inspire a elaboração de estudos socioeconômicos em outros territórios, possibilitando o reconhecimento das condições de vida, a trajetória das/dos assentados/as, subsidie as reivindicações pelo acesso a políticas públicas e contribua com a auto-organização e desenvolvimento dessas comunidades.

\section{Para iluminar a reflexão}

Quando propomos a construção de diálogos com experiências organizativas de movimentos sociais e populares, é importante tornar visíveis as chaves teóricas que iluminam nossas reflexões e ações. Tratando-se da perspectiva deste grupo, e consequentemente implicada na construção do instrumento que estamos apresentando, um dos objetivos fundamentais provém do campo da educação popular e sua relação com a auto-organização dos territórios.

Neste caminho,

Estamos convencidos de que qualquer esforço de educação popular [...] seja no campo agrícola ou no industrial urbano, deve ter, pelas razões até agora analisadas, um objetivo fundamental: através da problematização do homem-mundo ou do homem em suas relações com o mundo e com os homens, possibilitar que estes aprofundem sua tomada de consciência da realidade na qual e com a qual estão (Freire, 2020, p. 39).

Trata-se de propostas que se alimentam de um horizonte de transformação da realidade, "que não para, estoicamente, no reconhecimento puro, de caráter subjetivo, da situação, mas pelo contrário, que prepara os homens, no plano da ação, para a luta contra os obstáculos à sua humanização" (Freire, 2016, p. 186).

Este educador, também nos alerta sobre a necessária investigação temática em torno de áreas e assuntos que constituem as ações político-pedagógicas propostas. Os temas geradores devem ser pinçados da própria realidade vivida pela comunidade, experimentada no "chão" do assentamento, e podem trazer potentes contribuições para a leitura crítica da vida comunitária, sua relação com a sociedade e com as lutas sociais. Assim, utilizamos essa diretriz para pensar a necessária investigação ou descodificação das condições concretas de vida do território, visando contribuir para o fortalecimento de iniciativas auto-organizativas das/os assentadas/os e acampadas/os em torno de suas necessidades, como também apontando a importância da participação e do controle social popular das políticas públicas, especialmente as locais.

Dessa forma, fomos ensaiando a concepção de que a construção do instrumento para o conhecimento da realidade da comunidade não pode ser 
estabelecida pela transposição mecânica de questões abstratas, comumente previstas nos estudos socioeconômicos padronizados. O diálogo, a aproximação respeitosa, construtiva e comunicativa, as vivências junto ao território, a troca de saberes, a consideração de trajetórias de vida dos sujeitos, os parâmetros que o MST considera na construção de um assentamento, foram momentos que nos ajudaram a repensar, reelaborar e organizar as informações que constavam no instrumento.

Podemos dizer assim que a construção desta ferramenta metodológica na perspectiva da educação popular desenha possibilidades de percepção de inéditos viáveis que partam da identificação das situações-limites, geradoras de suas necessidades - nas formulações de Freire (2016) -, mas que vai além, conectando-se aos desafios político-organizativos do território, no contexto da luta pela terra e por uma outra forma de vida social.

Nesta perspectiva o inédito viável é ancorado a um projeto coletivo como possibilidade de transcender o adestramento técnico implícito em diagnósticos que se resumem ao levantamento de informações e medidas de avaliação sem investir na capacidade de indignação, denúncia, resistências populares na construção de projetos coletivos (Cf. Paro, Ventura e Silva, 2019). Neste caminho, apreender expressões da questão social via sistematização de informações (e situações-limite) possibilita edificar uma proposta pedagógica que não é apenas instrumental, mas ferramenta de luta política.

Dessa forma, "decifrar a questão social é também demonstrar as formas particulares de luta, de resistência material e simbólica acionadas pelos indivíduos sociais frente à questão social" (lamamoto, 2007, p. 59). Esta perspectiva nos permite dar uma ênfase especial aos traços de luta e resistência que perpassam as expressões da questão social que se fazem presentes num assentamento ou acampamento, possibilitando: a) a compreensão da importância dos processos de auto-organização das/dos trabalhadoras/es e demais segmentos subalternos, para dar resposta a suas próprias necessidades de sobrevivência; b) a identificação da relação que existe entre estas lutas sociais e a conquista de direitos ao longo da história de organização das/os trabalhadoras/es do campo, sendo estes processos constitutivos da consolidação da cidadania; c) a problematização dos padrões de intervenção do Estado frente a essas desigualdades e conflitos - que se materializam como políticas públicas e sociais - tendo como referência as demandas, reivindicações e necessidades sociais desses sujeitos coletivos.

Perguntamo-nos: essas políticas atendem às necessidades de reprodução dessas comunidades beneficiadas pela Reforma Agrária? Elas garantem direitos sociais para a população camponesa? Ou elas se configuram como relações clientelistas, tendentes ao apaziguamento e silenciamento das tensões e conflitos?

$\mathrm{Na}$ medida em que os subalternos se organizam através de movimentos sociais e organizações populares para lutar pelos seus direitos e suas condições de vida, podem tensionar os mecanismos estatais de enfrentamento das expressões da questão social. Ao mesmo tempo, esta perspectiva de análise do significado político das políticas sociais a partir das lutas sociais dos subalternos, possibilita dar visibilidade às disputas e contradições que perpassam o seu processo de formulação 
e implementação: as políticas sociais são sempre produto de relações de força que expressam tensões de classe (Cf. Marro, 2014).

Acampamentos e assentamentos de Reforma Agrária são territórios onde trabalhadoras/es rurais ensaiam tentativas de reprodução da sua existência na contramão das relações de produção hegemônicas, advindas do agronegócio. Ditos territórios, supõem uma intensa vida comunitária que envolve a produção, a organização do espaço e o convívio social, a capacitação, a formação política e humana e se traduz em cooperativas, associações, mutirões, feiras, campanhas, construção de moradias, mas também na prática permanente de resolução coletiva de necessidades. São espaços onde se experimenta a auto-organização coletiva para a conquista de melhores condições de vida e de trabalho, ressignificando trajetórias de vida marcadas pela pobreza e a negação dos direitos mais elementares. Apesar dessa complexa realidade, acampamentos e assentamentos são territórios em disputa, onde luta-se para a reconstrução da sociabilidade da classe e se tenta construir outro tipo de relações humanas; nesse sentido, falar em território tem um significado muito mais profundo que "propriedade" ou "posse" da terra.

Estas referências foram fundamentais para pensar que estudos socioeconômicos e de saúde, ou outras atividades orientadas ao conhecimento, sistematização e visibilidade das condições de vida de acampadas/os e assentadas/os poderiam subsidiar o protagonismo e a organização coletiva destes sujeitos, potencializando suas reivindicações e lutas por direitos. Isso nos desafiou a elaborar estratégias profissionais nas nossas áreas que dialogassem com as práticas históricas de auto-organização deste movimento social.

Ao buscar referências no programa agrário do MST que apresenta a pauta da Reforma Agrária Popular, encontramos elaborações que dizem respeito às condições de vida: "O campo deve se constituir num local bom de viver. Onde as pessoas tenham direitos, oportunidades e condições de vida dignas" (MST, 2013, p. 37). O processo de construção dos espaços de moradia deve respeitar as especificidades da cultura camponesa de cada região, constituindo-se como territórios que devem permitir o acesso a todos os direitos sociais, previdenciários e trabalhistas garantidos e equivalentes aos trabalhadoras/es urbanos.

Isso nos mostra que na luta pela terra, as famílias e pessoas beneficiadas pela Reforma Agrária almejam o acesso à terra, ao emprego e renda, à moradia, assim como melhores condições dignas de vida e de saúde. Portanto, envolve um conjunto enorme de necessidades que contemplam habitação; espaços de lazer; infraestrutura comum; abastecimento de água potável para o consumo e de água para irrigação produtiva; políticas de apoio à produção com base no princípio da soberania alimentar (livres de agrotóxicos e sementes transgênicas), mas também aquelas que apoiam a compra dos produtos alimentícios da agricultura camponesa por parte do Estado. Supõe também acesso a um conjunto de políticas públicas e sociais, tais como políticas de permanência no campo para juventude; políticas de proteção para os idosos (no âmbito previdenciário e assistencial); políticas de acesso à educação para toda a comunidade e em todos os níveis - educação para, do e no campo (cf. Caldart, 2004). 
São necessidades que emergem de propostas de Reforma Agrária mais integrais, construídas pelos movimentos sociais do campo que reelaboram sua luta à luz das condições de enfrentamento de um modelo de agricultura que se aprofunda no contexto da ofensiva neo-extrativista. Frente a um modelo que responde às necessidades do mercado externo e à dinâmica de financeirização e transnacionalização econômica, os movimentos sociais do campo vêm afirmando outros tipos de Reforma Agrária - no caso do MST, a Reforma Agrária Popular - que contemplam democratização da terra, soberania alimentar, agroecologia, alimentos saudáveis para o conjunto dos trabalhadores e o horizonte de novas relações sociais. Foram estas as referências que nos subsidiaram na construção de um instrumento que, acreditamos, reúne um conjunto de informações relevantes para o conhecimento, a sistematização e a organização de aspectos centrais à reprodução e organização da vida comunitária e produtiva própria de um assentamento ou acampamento de Reforma Agrária.

\section{Adapte, use e reutilize}

$\mathrm{Na}$ construção deste instrumento metodológico, além das informações reunidas em questionários que subsidiam estudos socioeconômicos mais padronizados, fomos contemplando outros elementos importantes para a consolidação do assentamento e em diálogo com as particularidades daquela comunidade. Apesar do seu caráter mais quantitativo - que responde à necessidade de organização das informações, de modo a subsidiar a construção de intervenções do poder público -, a ferramenta pode ser "recortada", "ampliada" e adaptada a outras demandas.

Por exemplo, em relação à educação, o instrumento considera não apenas o acesso à educação escolar, mas uma concepção mais ampla que caracteriza as práticas do MST (envolvendo a formação política, a participação na vida política local), mas também aspectos como a presença de equipamentos educativos com Educadoras/es que trabalhem os princípios da educação do campo; transporte para o acesso a outros níveis de educação (médio e superior). Em relação às práticas de cuidado da saúde, consideramos informações sobre a criação e cultivo de ervas e plantas medicinais. Há outros aspectos que não contemplamos, mas que dependendo do momento de consolidação do assentamento, poderiam ser relevantes e ganhar mais visibilidade nas perguntas do instrumento. Por exemplo, perguntas que destacassem necessidades específicas de políticas públicas para o apoio ao manejo florestal ou à agricultura camponesa; informações sobre sementes ou outras dimensões da soberania alimentar (necessidades de certificação e selos dos produtos orgânicos); considerando que estes elementos também podem compor e caracterizar dimensões das desigualdades socioeconômicas. Inclusive, na hora de sistematizar informações sobre a infraestrutura comum, poderiam considerar-se bibliotecas, serviços de informática, espaços culturais e de lazer em todas as áreas de assentamentos, voltados para o acesso, difusão, produção e intercâmbios esportivos, artísticos e culturais - que são aspectos presentes no programa agrário do MST. 
Como todo questionário ou processo de entrevista, ele demanda um preparo especial prévio da equipe que executará o trabalho, sobretudo considerando as relações de confiança com a comunidade, a postura ética e respeitosa em relação às informações, a atitude atenta ao sujeito da entrevista (sua fala, suas emoções, suas posturas e atitudes em relação à informação que nos brindam), dentre outros aspectos importantes.

Sugerimos complementar então com algumas referências importantes no âmbito da pesquisa social e qualitativa que possam subsidiar o preparo da equipe, como Gil (1999); Marconi \& Lakatos (2007) e Minayo (2007). Abaixo apresentamos nossa proposta. Se inspire, adapte, use e reutilize com as particularidades das suas comunidades.

Instrumento para Estudos Socioeconômicos

1. Identificação

1.1Nome (nome social)

1.2 Núcleo de base:

1.3 Data de nascimento:

1.4 Idade: anos

1.5. Como se identifica (autodeclara) em termos de cor/raça/etnia I__ preto |_|pardo I__indígena |_|branco I__amarelo

1.6 Identidade de gênero: . 1.7 Orientação sexual:

1.8 Estado civil: I__ solteiro I__casado I__amaziado I_|separado I__viúvo | - loutro

1.9 Documentação:

1.9.1 Possui RG? I_ $\mid$ Sim |_| Não 1.9.2 Possui CPF? I_|Sim |_|Não 1.9.3 Possui Título de Eleitor? I_ $|\operatorname{Sim}| \_\mid$Não 1.9.4 Possui CTPS? I_|Sim I_| Não

1.10 Religião: I_levangélica I_|católica I_lumbanda I_|candomblé I_l espírita I__ nenhuma I__outra

1.11 Contato telefônico? ( ) ___ _ _ _ _ _ _ _ _ _ _ _ _ _ _ _ _ possui.

$1.12 \mathrm{E}-\mathrm{mail}$ ? |Não possui.

\section{Composição Familiar}

2.1. Registrar a composição familiar abaixo incluindo a/o entrevistado, grupo considerado como núcleo familiar pelo entrevistado, morando ou não no assentamento. 


\begin{tabular}{|l|l|l|l|l|}
\hline Nome & Idade & Parentesco/Vínculo & Escolaridade & Ocupação \\
\hline 1. & & & & \\
\hline 2. & & & & \\
\hline 3. & & & & \\
\hline
\end{tabular}

2.1.2 Se tem filho(a), mora no assentamento? |__ Sim I__ Não

2.1.2 Se não mora no assentamento onde residem? |__ Zona urbana |_| Zona rural

3. Trajetórias de Migração

3.1 Em que município/estado nasceu?

- I__ Zona urbana I__ Zona rural

3.2 Em que município/estado morava antes de ingressar no acampamento? . I__ Zona urbana I__ Zona rural

3.3 Há quantos anos mora nesse município (onde se localiza o assentamento)? I__ menos de $1 I_{\ldots}\left|1 I_{\ldots}\right| 2 I_{\ldots}\left|3 I_{\ldots}\right| 4 I_{\ldots} \mid 5$ ou mais

3.4 Já precisou mudar de município e/ou estado para buscar trabalho/emprego: |__ Sim I__ Não

3.4.1 Se sim, quantas vezes? I_ $|1| I_{-}|2| \ldots|3| \ldots \mid 4$ ou mais

3.4.2 Se sim, nessa(s) situação(ões) sua família geralmente muda junto? I_ | Sim | - $\mid$ Não

3.5 Há quantos anos mora nesse assentamento? I_ $\mid$ menos de 1 I_ $\mid 1$ I_ $\mid 2$ I_ 3 I__l I_l5 ou mais

3.6 Durante quantos anos ficou acampada/o? I_Imenos de 1 I_ $|1|_{\text {_ }}|2|_{\text {_ }}$ I_l I I_ 15 ou mais

3.7. Sofreu algum despejo no acampamento ou assentamento? |_|Sim I_|Não 3.7.1 Se sim, foi realizado de forma violenta/repressiva? I__Sim I_|Não

4. Condições de Moradia e Infraestrutura

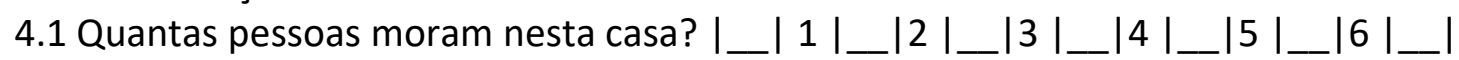
7 ou mais

4.2 Localização da moradia I__área sem risco I__ com risco de alagamento I__ com risco de deslizamento I__ com risco de desabamento I__ outra

4.3 Construção da moradia: I__ completa I__ em andamento I__a construir 4.4 Método de construção da moradia: I__empreiteiras vinculadas a programa de financiamento I__ contratação de serviços privados I_lindividualmente I_l mutirão |__Outra

4.5 Tipo de financiamento envolvido: I__ recurso próprio I__PRONAF I__ programa de financiamento da agricultura familiar estadual I_|programa de financiamento agricultura familiar municipal I__ outro

4.5.2 Há contrapartida no financiamento? I__ sim I__ não

4.5.3 Se sim, qual?

4.6 Material da construção: I_ | Alvenaria com revestimento I_|Alvenaria sem revestimento I__ Lona I__ Madeira aparelhada I__Madeira aproveitada I_l Pau-a-pique I__ Reciclagem |__|Outro:

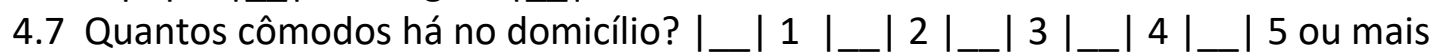


4.8 Qual a principal forma de iluminação do domicílio: rede elétrica gerador ou energia solar Vela I__ Lanterna I__ Outra | Óleo, querosene ou gás de botijão |_l

4.9 Esgoto: |rede geral de esgoto ou pluvial | fossa séptica | fossa rudimentar |vala | |rio, lago ou mar loutro escoadouro

4.10 Banheiro dentro da casa? I__ $\mid$ Sim I__ Não

4.11 A água utilizada do domicílio vem de: I__ Rede geral de distribuição Poço ou nascente na propriedade I Poço ou nascente fora da propriedade I__ Carro pipa I__ I Água da chuva armazenada em cisterna I__ Água da chuva armazenada de outra forma I__ l Rios, açudes, lagos I__ Outra. Qual?

4.12 Vocês precisam comprar água? I__ $\mid$ sim $\mid \_$_ não |__as vezes.

4.13 A água utilizada em sua residência é suficiente para as necessidades domésticas de sua família? |__ $\mid$ sim |__ | não |__ | não sabe informar

4.14 Há reaproveitamento do lixo orgânico do domicílio para fins de adubação da terra? | |Sim | |Não | Em parte

4.15 o lixo descartado deste domicílio é: I___coletado diretamente por serviço de limpeza I__ l colocado em caçamba de serviço de limpeza I__lqueimado (na propriedade) I___enterrado (na propriedade) I__ljogado em terreno baldio ou logradouro I__ljogado em rio, lago ou mar $I_{\text {__ }} \mid$ tem outro destino. Qual?

4.16 Equipamentos em casa (marque todos que tiver): I__ geladeira | _ $\mid$ fogão |

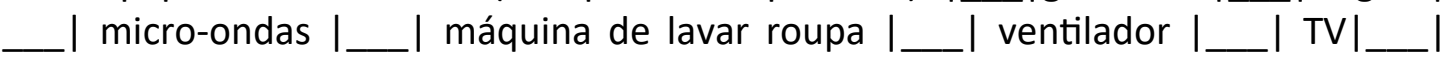
DVD $\mid \ldots \ldots$ computador com acesso a internet $\mid \ldots \ldots$ computador sem acesso à internet I__ lar-condicionado I__ l tanquinho

4.17 Tem acesso à telefonia no assentamento? |__ $\mid$ sim I__ não

4.18 Internet? |__ $\mid$ sim I__ | não

4.19 Principal meio de transporte: $\mid \ldots$ _ carro individual $\mid \ldots$ _transporte público |__ bicicleta |__ moto |__ | carroça/cavalo |__outros

\section{Trabalho e Renda}

(Neste bloco, pode-se avaliar que, caso se trate de um mesmo grupo familiar, os itens 5.1 a 5.4 sejam respondidos individualmente, e a partir do item 5.5, respondidos apenas por um dos membros do grupo)

5.1 Habilidades e Ofícios: |__ Operadora/o de máquina/serviços de mecanização em geral I__|Preparo de derivados de leite I__Serviços de: ordenha e manejo de rebanho I_Imarcenaria I_|construção civil (especificar:

agricultura I__ |artesanato em geral |__ $\mid$ serviços domésticos |__ culinária | panificação I_l condução de transportes Outros

5.2 Ocupação anterior ao assentamento: I__desempregada/o I__assalariada/o formal urbano I__assalariada/o formal rural I__mercado informal urbano I__ mercado informal rural IOutro

5.3 A ocupação anterior atendia satisfatoriamente as necessidades da família? Sim | Não 
5.4 Doenças e/ou acidentes de trabalho anterior? Sim |Não 5.4.1 Se sim, qual(s)? I__ | transtorno de saúde mental lestresse |__lesões físicas |fraturas lOutros

5.5 Qual a principal fonte de renda familiar atualmente? Agricultura Artesanato I__|Programas/projetos do poder público I__ Nenhuma |_|Outro 5.6 Qual valor aproximado da renda familiar? I__menos que $1 \mathrm{SM}$ I_ $\mid 1 \mathrm{SM}$ |_ I $1,5 \mathrm{SM} I_{\_}\left|2 \mathrm{SM} I_{-}\right| 2,5 \mathrm{SM} I_{-} \mid 3 \mathrm{SM}$ ou mais

5.7 Algum membro tem fontes de renda externa às atividades produtivas do assentamento? I__ $|\operatorname{Sim}| \ldots \mid$ Não

5.7.1 Se sim, qual é a fonte da renda? I__assalariada/o urbano I__assalariada/o em atividades rurais externas ao assentamento I__ Atividade informal urbana I_l Atividade informal na zona rural I__ Outra

5.7.2 A renda gerada fora do assentamento é :

I__ maior que a gerada dentro I__ igual à gerada dentro I_ | menor que a gerada dentro I__ varia

5.8 A sua produção como assentada/o é: I__ exclusivamente para subsistência

I_lcom excedente para troca na comunidade I_lpara subsistência e comercializada no mercado local I__ para subsistência e comercializada I__Outro 5.9 Participa de produção coletiva/associada/cooperada? I__Sim |_| Não 5.10 Qual a fonte de água utilizada para a produção agrícola? I__ l Rede geral de distribuição I__ l Poço ou nascente na propriedade I__ | Poço ou nascente fora da propriedade I__ I Carro pipa I__ I Água da chuva armazenada em cisterna

I__ I Água da chuva armazenada de outra forma I__ l Rios, açudes, lagos I__ Outra. Qual?

5.11 Recebe algum tipo de assistência técnica? I__nenhuma I__familiares ou amigos I__ poder público local I_l empresa pública I_lempresa privada I_l ONG I__ sindicato I__ cooperativa

5.12 Fontes de financiamento da produção agrícola: I__nenhum I_|banco privado I_Ifornecedor da matéria-prima I_|cooperativa I_|comprador do produto |__crédito informal I__ONGs I__Pronaf I__outro crédito público I_l outro:

5.13 Principais dificuldades para produzir: I__estradas I_|terras fracas ou degradadas I_lacesso à água I__comercialização I_lclima I_|diminuição da produtividade I__assistência técnica I__ Acesso à energia elétrica |_l crédito I__outros

$5.14 \mathrm{Na}$ produção faz uso de: I__Biofertilizante (produção orgânica) I__ Fertilizante industrial |__Parte orgânico, parte industrial

5.15 Tem diversificação na produção? I__ Sim I__ Não

5.16 Já aconteceu da comida acabar antes que tenha produção ou dinheiro para comprar mais? I_ $\mid$ Sim, sempre I_ $\mid$ Sim, as vezes I_|Não

\section{Acesso às Políticas Públicas}

6.1. Como acessa os serviços de saúde, assistência, educação ou outros? I__ existência de equipamentos públicos no assentamento I__lequipamentos públicos 
externos ao assentamento |existência de equipamentos públicos itinerantes que visitam o assentamento

6.2. Possui Cartão do SUS? I__ Sim I__ Não

6.3. $\quad 6.3$ Possui CADÚNICO? I_ | Sim I_l Não

6.4. Inserida/o em algum programa/projeto assistencial? |__Sim |_|Não

6.5. Recebe algum benefício assistencial de transferência de renda? I__ BPC I__ Bolsa Família I_l Benefício Municipal I_l Outro____ I Nenhum.

6.6. Recebe algum benefício previdenciário? I__aposentadoria I_|pensão |__ auxílio desemprego I__auxílio doença I_lauxílio reclusão I__aposentadoria na condição de produtor rural

6.7. É inserida/o em algum programa/projeto do poder público específico para trabalhadores rurais? I__PNAE |_| PAA |_| Outro |_|Não

6.8. Como se desloca para acessar os equipamentos públicos? I_la pé I_lde bicicleta I_ltransporte coletivo público I_lautomóvel individual I__ carroça/cavalo I__outros

6.9. Participa ou já participou de conselhos de direitos ou conferências? I_|Sim I__ Não

6.10. Sabe ler e escrever? |_ $|\operatorname{Sim}| \ldots \mid$ Não $\left|\_\right|$com dificuldade

6.11 Grau de escolaridade I__ Não alfabetizado I__Somente lê e escreve I__ Ensino Fundamental incompleto I__ Ensino Fundamental completo I_l Ensino Médio incompleto I__Ensino Médio completo I_|Curso Técnico Subsequente ao E. Médio incompleto I__Curso Técnico Subsequente ao E. Médio completo I_l Ensino Superior incompleto

I__ Ensino Superior completo

6.12. Estuda atualmente? I__ $\operatorname{Sim}$ I__ Não

6.12.1 Se não, gostaria? I__ Sim I_|Não

6.12.2 Se sim, onde se localiza o equipamento? I__ no assentamento I__fora do assentamento, mas na zona rural I__ fora do assentamento, na zona urbana

6.12.3 Se sim, como se locomove até escola/curso? I__a pé I__bicicleta I_l transporte coletivo I__ carona I__ Outros

6.13 Há oferta de atividades esportivas, culturais e/ou lazer pelo poder público no assentamento ou proximidades? I__ $\mid$ Sim |__ Não

6.13.1 Se não, gostaria? I_| capoeira I_|dança I_| teatro I_|música I_|yoga | _ | futebol I__ vôlei |__ginástica |__outros

6.14 Tem acesso às políticas para as mulheres? (no caso da ficha específica para elas) |__ grupo de geração de renda I__ | prevenção e enfrentamento da violência |_l saúde da mulher I__ programas de enfrentamento da desigualdade de gênero I_l Outros

7. Saúde

7.1 Antecedentes familiares (aplicam-se a mulheres, homens e crianças):

\begin{tabular}{|l|l|l|l|}
\hline Doença & Sim & Não & Parentesco \\
\hline Diabetes & & & \\
\hline Hipertensão & & & \\
\hline
\end{tabular}




\begin{tabular}{|l|l|l|l|}
\hline Tuberculose & & & \\
\hline Cardiopatias & & & \\
\hline Alergias & & & \\
\hline Câncer & & & \\
\hline Problemas renais & & & \\
\hline DST & & & \\
\hline Próstata & & & \\
\hline Outros/ especificar & & \\
\hline
\end{tabular}

7.2 História pregressa (aplica-se a mulheres e homens deste item 7.2 ao 7.13, observando as especificidades dos subitens 7.2.1, 7.2.2 e 7.2.3):

Doenças anteriores: I_ | Sim I_|Não Quais:

Hipertensão: I_ $\left|\operatorname{Sim} I_{\_}\right|$Não Diabetes: I_l Sim I_|Não

DST/AIDS I__ Sim I__ Não Quais:

Uso de medicamentos: I__ Sim I_|Não Quais:

Atividade física: I_|Sim I_|Não Tabagismo: I_|Sim I_|Não Uso de álcool: I__Sim I_l Não

Intestino:

7.2.1 Se for homem cis - Controle da Próstata I__Sim I__Não Último exame:

7.2.2 Se for mulher cis - Antecedentes obstétricos:

Menarca:

Início de relações sexuais: . Uso de métodos contraceptivos:

Em caso de gestação, idade da primeira gestação:

Gesta: Para: Abortos:

Última citologia oncótica:

Mamas:

DST/AIDS:

Ginecológica:

7.2.3 Se for criança - Exame físico:

Peso: . Altura:

. IMC:

Pele: Regularidade ao pediatra:

Vacinação: (sugere-se incluir quadro de vacinação na utilização do instrumento para registro de vacinas)

7.3 Faz uso de medicamento contínuo? |__ Sim I__Não

7.4 Como acessa os medicamentos: I__ Farmácia Popular I__|Programa Estratégia de Saúde da Família I__Compra na farmácia com recurso próprio I_|Outros

7.5 Alimenta-se satisfatoriamente? I__ Sim I__ Não

7.5.1 Quantas refeições por dia? $I_{-}|1| \_|2| \_|3| \_\mid 4$ ou mais

7.5.2 Frutas? |_ $\mid$ sim |__não |_las vezes

7.5.3 Legumes/verduras? I__ $\operatorname{sim} \mid$ _ $\mid$ não |_las vezes

7.6 Qual as fontes de água para beber? I__ encanada I__mineral I_|cacimba I _lpoço I__rio

7.7 Qual as fontes de água para cozinhar? I__ encanada I__mineral I__ cacimba I__poço I__rio 
7.8 Faz uso de plantas medicinais? I__ $\operatorname{sim} \mid$ _ $\mid$ não

7.8.1Se sim, quais?

7.9 Como avalia a sua capacidade de enxergar? (com óculos ou lentes, se usar) I__ incapaz I__ grande dificuldade permanente I_l alguma dificuldade permanente I__ nenhuma dificuldade

7.10 Identifica necessidades de cuidados odontológicos? I__ |Sim I__ Não

7.10.1 Se sim, quais? I__prótese |__extração do ciso |__obturação de cáries | __ gengiva |__loutros tipos de cuidado/reparação

7.11 Exame físico:

Peso:

Altura:

PA:

FC:

FR:

Queixas e observações?

7.12 Saúde Mental

(A abordagem sobre saúde mental pode ser delicada e difícil de obter respostas diretas. As perguntas propostas podem nos levar a um diálogo com a/o entrevistada/o, aprofundando as situações na hora da entrevista, por exemplo: em que contexto aparece a tristeza, o medo, o choro, permitindo perceber situações de violência doméstica depressão, uso abusivo de álcool. As respostas obtidas podem possibilitar acompanhamento e orientação às familias.)

7.12.1. Você sente tristeza? I_ l em poucos momentos I_lalgumas vezes I_l sempre

7.12.2. Você tem vontade de chorar? I__em poucos momentos I__algumas vezes I__ sempre

7.12.3. Você fica nervoso, irritado? I__ em poucos momentos I_|algumas vezes | | sempre

7.12.4. Você sente medo? I__ em poucos momentos I_l algumas vezes I_l sempre

7.12.5. Você usa bebida alcoólica? I__ em poucos momentos I__ algumas vezes | _ sempre I__ Não

7.12.6. Faz uso de outras drogas? I__ em poucos momentos I__ algumas vezes | _lsempre I__ Não

7.12.7. Você vive algum transtorno mental diagnosticado? I_ | Não I_ $\mid$ Sim, ansiedade I_|Sim, depressão I_ Sim, síndrome do pânico I_l Sim, outro(s)

7.12.8. Faz uso de medicação controlada? |__ Sim I__ Não

8. Relações de Gênero

8.1. Se for mulher - Já sofreu alguma situação de violência? |__ $|\operatorname{sim}|$ _ $\mid$ não

8.1.1 Se sim, qual? I_Ifísica I_Ipsicológica I_ Isexual |econômica/financeira I__institucional I__loutra

8.2 Aplica-se a todas as pessoas: Participa ou já participou em atividades de coordenação e representação do Movimento? |__ | sim |__ |não

8.3 Aplica-se a todas as pessoas: Participa de eventos externos (cursos, seminários, reuniões, etc.)? $|\operatorname{sim}|$ Inão 
8.4 Aplica-se a todas as pessoas: Como é a organização do trabalho doméstico? | |dividido entre todos os membros da família |__ | realizado pelas mulheres da casa I. | realizado exclusivamente por você (mulher) | IOutros

8.5 Aplica-se a todas as pessoas: Como é organizado o trabalho produtivo?

com expressiva participação das mulheres no planejamento e na execução do trabalho produtivo I___ com pouca expressividade da participação das mulheres no planejamento e na execução do trabalho produtivo

I___ sem a participação das mulheres no planejamento e na execução do trabalho produtivo I___outro

8.6 Aplica-se a todas as pessoas - Como se organiza financeiramente? |renda própria |___ |renda dx cônjuge | |renda compartilhada |Outros

8.7 Aplica-se a mulheres cis e pessoas cujo gênero/orientação sexual não for heteronormativa: Já sofreu situações de discriminação? $|\operatorname{sim}|$ |não 8.7.1. Se sim, qual?

8.8 Aplica-se a mulheres cis e pessoas cujo gênero/orientação sexual não for heteronormativa: Já sofreu situações de discriminação? |__ _ sim |__ não 8.7.1. Se sim, qual?

9. Vínculo e Relação com o Movimento

9.1 Como chegou ao movimento? I__ ITrabalho de base I__ Sindicato I__ I Outros movimentos sociais |Outros

9.2 Cumpre ou cumpriu funções de direção do movimento? $|\operatorname{sim}|$ |não

9.2.1 Se sim, quais?

9.3 Participa dos espaços organizativos do assentamento (assembleias, reuniões de núcleo, mutirões)? | $|\operatorname{sim}|$ | não

9.4 Participa de eventos e encontros externos? $|\operatorname{sim}|$ |não

9.4.1 Se sim, quais?

9.5 Participa ou já participou de cursos de formação oferecidos pelo movimento? | |sim I__ | não

9.5.1 Se sim, qual(s)?

Data:

Responsável pelo preenchimento do questionário:

\section{Reescrevendo a palavra (e o mundo): aprendizados para a formação profissional}

Um dos aprendizados mais importantes que gostaríamos de destacar é a vivência das condições de vida e o conhecimento das formas de organização - nas suas riquezas e contradições - das classes subalternas, a partir da experiência concreta de um acampamento e um assentamento Sem Terra. O contato com as condições de vida dessas famílias; o estudo para a compreensão da questão agrária no Brasil e na região, na sua relação com as políticas públicas deu-nos a possibilidade 
de problematizar as manifestações da "questão social" nesse território de Reforma Agrária a partir dos processos de luta, trazendo interrogações acerca das formas de organização e resistência acionadas por esses sujeitos para dar resposta a suas necessidades e construir negociação com o poder público.

Apesar das inúmeras dificuldades e contradições que se observam nesses territórios, entendemos que é um espaço privilegiado para observar o fato de que as expressões da questão social e as reivindicações construídas por esses sujeitos não são passivas ou despidas de conflitos coletivos. São territórios fundamentais para aprender o significado das lutas coletivas para a conquista dessas políticas sociais, na perspectiva da ampliação da cidadania dos subalternos. Acreditamos que é também uma oportunidade de conhecer as/os usuárias/os dos equipamentos de políticas sociais onde trabalhamos Assistentes Sociais e Enfermeiros, na perspectiva de construção de propostas inovadoras de trabalho, para além de modelos assistenciais clássicos de administração da pobreza: assumindo o desafio de elaborar novas ferramentas, linguagens e estratégias comunitárias de abordagem das demandas sociais desses sujeitos; assim como também valorizando seus saberes e seu protagonismo na conquista dos direitos sociais.

O trabalho realizado numa perspectiva interdisciplinar; a aprendizagem dos instrumentos de assessoria técnica e política que o Serviço Social e a Enfermagem podem desenvolver junto aos movimentos sociais; a apropriação de instrumentos de mobilização e educação popular, utilizados para a realização das atividades de organização interna ou de saúde; oferecem possibilidades de formação profissional que abrem novas perspectivas de trabalho, pautadas na socialização do conhecimento socialmente produzido. Ensaiamos a construção de propostas de trabalhos com e não para os territórios: criando assim verdadeiras oportunidades de formação política, profissional e humana, pautadas na perspectiva dialógica e comunicativa que são pilares essenciais da educação popular.

Por ser produto de uma experiência de extensão universitária realizada junto a um movimento social como o MST, resgatamos as contribuições substantivas surgidas e os impactos progressivos na democratização e abertura dessa instituição às necessidades das classes subalternas, por exemplo, pautando novas agendas de ensino, pesquisa e extensão; contribuindo com o redimensionamento crítico da formação universitária de docentes, estudantes e profissionais; promovendo a construção de criações coletivas de trabalho que enriquecem a vida políticoacadêmica e a função social da universidade pública. Desafiamos modelos tradicionais de extensão, que reproduzem práticas de tutela que pretendem equivocadamente "estender algo desde a 'sede do saber' até a 'sede da ignorância' para 'salvar', com este saber, os que habitam nesta" (Freire, 2020, p. 25).

\section{Referências}

ALMEIDA, R. R. de. Construindo promoção e prevenção em saúde num

assentamento do MST. 2015. Trabalho de Conclusão de Curso (Graduação em Enfermagem)- Campus de Rio das Ostras, Universidade Federal Fluminense, Rio das Ostras, 2015. 
ALVES, Hayda, BARBOSA, Elizabeth, MARRO, Katia, DULCICH, Ramiro. Uso de metodologias participativas com famílias do Movimento Sem Terra (MST): um estímulo à organização coletiva e à promoção da saúde. I SIMPÓSIO INTERNACIONAL DE METODOLOGIAS PARTICIPATIVAS NA CONSTRUÇÃO DO CONHECIMENTO, 2015, São Paulo, Anais..., São Paulo - SP, 2015.

CALDART, Roseli. Pedagogia do Movimento Sem Terra. São Paulo, Expressão popular, 2004.

FREIRE, Paulo. Pedagogia do Oprimido. 60. ed.. Rio de Janeiro: Paz e Terra, 2016.

FREIRE, Paulo. Extensão ou Comunicação? 22. ed. Rio de Janeiro: Paz e Terra, 2020.

GIL, Antonio. Métodos e técnicas de Pesquisa Social. São Paulo: Atlas, 1999.

IAMAMOTO, Marilda. O Serviço Social na Contemporaneidade. São Paulo: Cortez, 2007.

IBGE, Questionário do Censo Demográfico 2000. Disponível em:

http://www.ibge.gov.br/censo/quest_amostra.pdf. Acesso em: 29 out. 2020.

MARRO, Katia. O que a universidade pode aprender quando coloca seus pés em um acampamento sem-terra? In: ABRAMIDES, Beatriz; DURIGUETTO, Maria Lúcia (Org.). Movimentos sociais e serviço social: uma relação necessária. São Paulo: Cortez, 2014, p. 278-294.

MARCONI, Marina; LAKATOS, Eva. Técnicas de pesquisa: planejamento e execução de pesquisas, amostragem e técnicas de pesquisas, elaboração, análise e interpretação de dados. 6. ed., 2. reimpressão. São Paulo: Atlas, 2007.

MINAYO, Cecília (org.). Pesquisa Social. Teoria, método e criatividade. 25. ed. Petrópolis-RJ: Vozes, 2007.

MIOTO, Regina. Estudos socioeconômicos. In: CFESS/ABEPSS. Serviço Social: Direitos Sociais e Competências Profissionais. Brasília: CFESS-ABEPSS, 2009.

MST. Programa Agrário do MST, 2013. Disponível em: https://mstbrasilien.de/wpcontent/uploads/2014/02/Cartilha-Programa-agr\%C3\%A1rio-do-MST-FINAL.pdf. Acesso em: jun. 2020.

MONTEIRO, Jéssica. Das trincheiras de contra-hegemonia em tempos sombrios: contribuições de uma experiência de extensão universitária com processos de formação política junto ao MST. 2014. Trabalho de conclusão de curso (Graduação) UFF, Rio das Ostras, 2014.

NETTO, José Paulo. Cinco notas a propósito da "Questão Social". In: Revista Temporalis. Brasília: Abepss-Grafline, ano 2, n. 3, 2001.

OLIVEIRA, Dayse. O Projeto de Desenvolvimento Sustentável (PDS) e os desafios para a construção de novas formas de assentamento: o caso do assentamento Osvaldo de Oliveira em Macaé. 2014. Trabalho de Conclusão de Curso (Graduação) UFF, Rio das Ostras, 2014. 
PARO, César Augusto; VENTURA, Miriam; SILVA, Neide Emy Kurokawa e. Paulo Freire e o Inédito Viável: esperança, utopia e transformação na saúde. In: Revista Trab.

educ. saúde, Rio de Janeiro, v.18, n.1, 2020. Disponível em:

http://www.scielo.br/scielo.php?

script=sci_arttext\&pid=S198177462020000100400\&lng=pt\&nrm=iso . Acesso em: 01 nov. 2020. 